\title{
Recent highlights in the synthesis of highly functionalized pyrimidines
}

\author{
Marco Radi, ${ }^{a}$ Silvia Schenone ${ }^{b}$ and Maurizio Botta ${ }^{* a, c}$ \\ Received 2nd April 2009 \\ First published as an Advance Article on the web 12th June 2009 \\ DOI: 10.1039/b906445a
}

The pyrimidine scaffold represents an important pharmacophore endowed with a wide range of pharmacological activities according to the specific decoration of the heterocycle. This perspective article will briefly outline the most interesting approaches recently reported for the synthesis of highly functionalized pyrimidine derivatives.

\section{Introduction}

Nitrogen-containing heterocycles are widely distributed in nature and are essential to life, playing a vital role in the metabolism of all living cells. Among these, pyrimidines represent one of the most prevalent heterocycles found in natural products such as amino acid derivatives (willardiine, tingitanine), ${ }^{1}$ vitamins (vitamin B1), ${ }^{2}$ antibiotics (bacimethrin, sparsomycin, bleomycin), ${ }^{3}$ alkaloids (heteromines, crambescins, manzacidins, variolins, meridianins, psammopemmins etc.), ${ }^{4}$ and toxins. ${ }^{5}$

From a synthetic point of view, the first pyrimidine derivative (alloxan) was obtained as early as 1818 , by Brugnatelli, oxidizing

aDipartimento Farmaco Chimico Tecnologico, Università degli Studi di Siena, Via Alcide de Gasperi 2, I-53100, Siena, Italy.E-mail: botta@unisi.it; Fax: +390577 234333; Tel: +390577234306

${ }^{b}$ Dipartimento di Scienze Farmaceutiche, Università degli Studi di Genova, Viale Benedetto XV, I-16132, Genova, Italy

'Sbarro Institute for Cancer Research and Molecular Medicine, Center for Biotechnology, College of Science and Technology, Temple University, BioLife Science Bldg., Suite 333, 1900 N 12th Street, Philadelphia, PA 19122, US

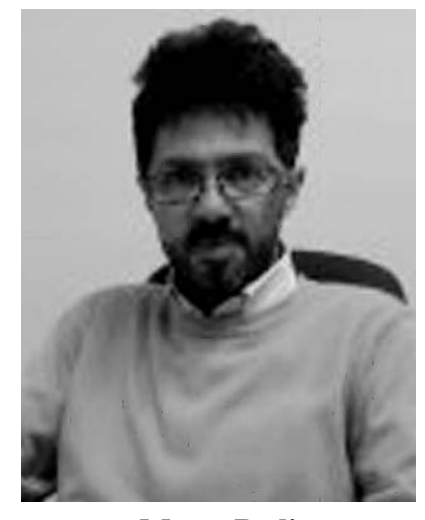

Dr Marco Radi obtained a degree in Medicinal Chemistry at the University of Siena (Italy) in 2000 working on the solid phase synthesis of pyrimidine nucleosides. In 2004 he received a PhD in medicinal chemistry from the University of Siena working on the synthesis of novel pyrimidines and pyrimidine-nucleosides as potential HIV-1 inhibitors. He spent one year as a postdoc at the University of Georgia (USA) working with Prof. David C.K. Chu on the synthesis of pyrimidine nucleosides (Troxacitabine prodrugs and Neplanocin A analogues) as anticancer and antiviral agents. Since January 2006 he has been working as Research Associate at the University of Siena in collaboration with Prof. Maurizio Botta. Radi's research interests are in the drug design and synthesis of antiviral and antitumor agents. uric acid with $\mathrm{HNO}_{3} .{ }^{6}$ In 1848 , a second pyrimidine synthesis was pioneered by Frankland and Kolbe, who heated propionitrile with metallic potassium to give a pure product (2,6-diethyl-5-methyl-4pyrimidinamine $)^{7}$, while in 1878 Grimaux prepared barbituric acid by condensation of malonic acid with urea. The latter procedure has been later named after Pinner who gave the name to the pyrimidine scaffold and was the first to understand the chemical nature of this structure.

Over the years, the pyrimidine system turned out to be an important pharmacophore endowed with druglike properties and a wide range of pharmacological activities depending on the decoration of the scaffold. A few illustrative examples of pyrimidine derivatives active as inhibitors of $\mathrm{HIV},{ }^{8} \mathrm{HCV},{ }^{9} \mathrm{CDK},{ }^{10}$ $\mathrm{CB} 2,{ }^{11} \mathrm{VEGFR}^{12}$ and Adenosine $\mathrm{A} 1 / \mathrm{A} 2 \mathrm{a} / \mathrm{A} 3^{13}$ are reported in Fig. 1. Due to the long-lasting interest in pyrimidine derivatives as potential drugs, the synthetic community has dedicated much effort to the investigation of new approaches to those derivatives. Accordingly, we will try to give an overview of the most interesting synthetic strategies recently reported for the generation of highly functionalized pyrimidines.

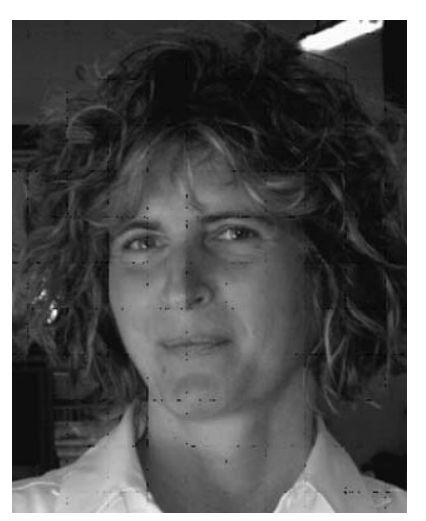

Prof. Silvia Schenone obtained a degree in medicinal chemistry in 1987 and in pharmacy in 1988 both with laude at the University of Genoa. In 1992, she received a PhD in medicinal chemistry and became a researcher in 1992. From 2001, she has been an associate professor of medicinal chemistry at the same university. At present, she is involved in the synthesis of thiadiazole derivatives endowed with analgesic and anti-inflammatory activities, the synthesis of pyrazolo-pyridine derivatives as adenosine antagonists and in particular of pyrazolo-pyrimidine derivatives as tyrosine $\mathrm{ki}$ nases inhibitors. Prof. Schenone's team is also involved in structural studies on biological macromolecules (enzymes, receptors, growth factors) and molecular modeling applications in medicinal subjects. 
<smiles>COc1ccc(CCSc2nc(C(C)c3c(F)cccc3F)c(C)c(=O)[nH]2)cc1</smiles><smiles>O=C(NCC1CCOCC1)c1cnc(Nc2ccc(Cl)cc2Cl)nc1C(F)(F)F</smiles><smiles>COc1ccc(F)c(C(=O)O)c1C(=O)c1cnc(NC2CCN(S(C)(=O)=O)CC2)nc1N</smiles>

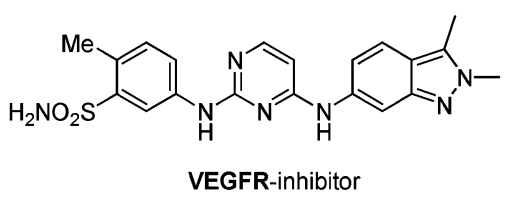<smiles>CCCC(=O)Nc1nc(-c2ccccc2)cc(-c2ccccc2)n1</smiles><smiles>COC[C@H]1CCCN1c1cc(NC(C)=O)nc(-n2nc(C)cc2C)n1</smiles><smiles>CCCSc1nc(NC(C)=O)cc(OCc2ccc(Cl)cc2)n1</smiles>

Fig. 1 Selected examples of recently reported pyrimidine derivatives with an interesting pharmacological profile.

\section{Convergent approaches}

As summarized in Scheme 1, the most interesting approaches developed so far for the convergent synthesis of highly functionalized pyrimidines can be classified according to the nature of the fragments that are joined together during the closure of the pyrimidine nucleus. The Pinner synthesis (path A, 1,6/ 3,4-bond forming) represents the most common approach and the heterocyclization usually involves a double condensation with elimination of water, alcohol or hydrogen halide. In recent years, several interesting Pinner-like aproaches have been developed: Karpov and Müller reported the employment of alkynones ( $\beta$-keto aldehydes' synthetic equivalents) in a three-component one-pot pyrimidine synthesis (Scheme 2). ${ }^{14}$ The coupling of acid chlorides (1) with terminal alkynes (2) under modified Sonogashira conditions ( $\mathrm{Et}_{3} \mathrm{~N}$ used in stoichiometric amount) followed by the addition of aminium or guanidinium salts (4) in the presence of sodium carbonate gave the 2,4-disubstituted or 2,4,6-trisubstituted pyrimidines $\mathbf{5}$. Terminal ethynyl ketones $\mathbf{3}$ are

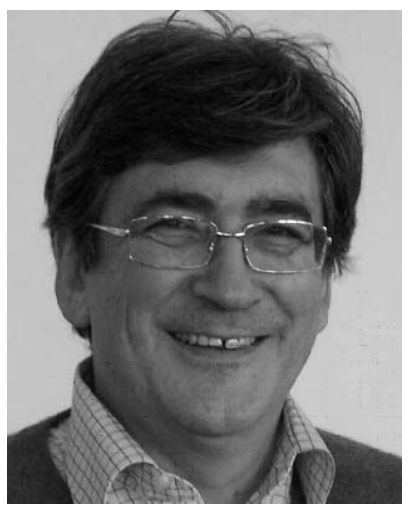

Maurizio Botta
Prof. Maurizio Botta obtained a degree in chemistry at the University of Rome in 1974. After working as a temporary assistant in organic chemistry at the University of Rome, he got a fellowship from the University of New Brunswick (Canada), where he earned his PhD in chemistry in December 1979 under the direction of Prof. K. Wiesner. He was invited researcher in the laboratory of Prof. S. Hannessian at the University of Montreal and in 1987 he became an associate professor of medicinal chemistry at the Faculty of Pharmacy of the University of Siena, where he has been a full professor since 2000. Since 2008 he has been an adjunct professor at the Sbarro Institute for Cancer Research and Molecular Medicine, Center for Biotechnology (SHRO, Temple University, Philadelphia, USA). Botta's research interests are in the drug design and synthesis of antiviral, antitumor and antifungal agents.

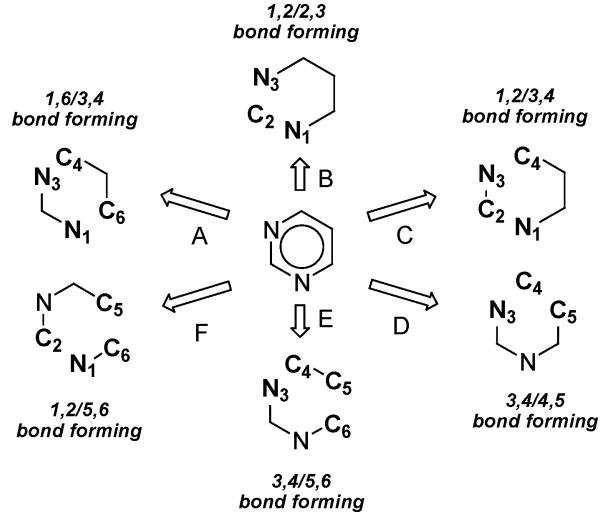

Scheme 1 Synthetic approaches for the synthesis of the pyrimidine scaffold.

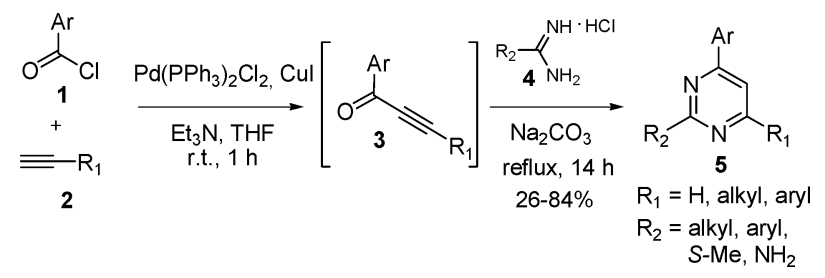

Scheme 2 Müller's synthesis of 2,4-disubstituted and 2,4,6-trisubstituted pyrimidines.

highly reactive, base sensitive species that do not need to be isolated under the modified Sonogashira conditions and can be reacted directly in the second step to give the desired pyrimidine derivatives. Alternatively, (trimethysilyl)ethynyl ketones $\left(\mathrm{R}_{1}=\right.$ $\mathrm{SiMe}_{3}$ ) can be prepared following the same procedure and isolated due to their higher stability. These isolated intermediates can be cyclized to give the pyrimidinones $5\left(R_{1}=H\right)$ in a two step protocol. $^{15}$

Bagley et al. published a microwave assisted condensation of readily available alkynones ${ }^{16} \mathbf{6}$ with an excess of the hydrochloride salt of substituted amidines 7 (Scheme 3). ${ }^{17}$ After cooling and filtration, the 2,4,6-trisubstituted pyrimidines $\mathbf{8}$ were obtained in a short time, with high yield and often with no need of further purification. The same group also reported a microwave assisted synthesis of 2,6-disubstituted pyrimidines 8 in a one-pot tandem oxidation-heteroannulation reaction starting from propargylic 


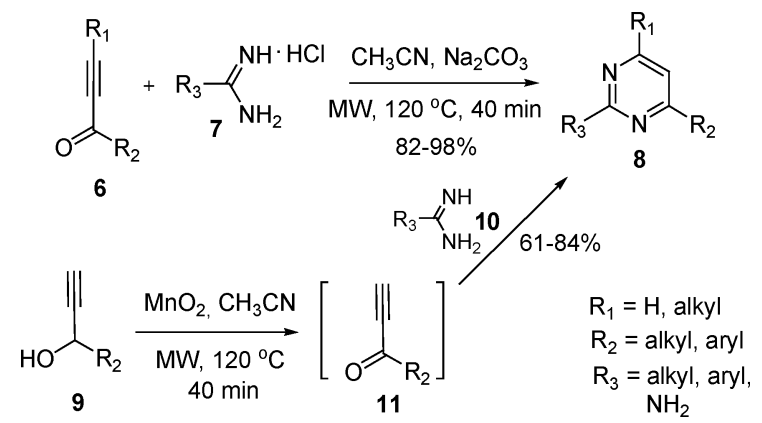

Scheme 3 Bagley's synthesis of 2,6-disubstituted and 2,4,6-trisubstituted pyrimidines.

alcohol 9 (Scheme 3): in situ oxidation with $\mathrm{MnO}_{2}$ provided the corresponding alkynones $\mathbf{1 1}$ which immediately reacted with the substituted amidines $\mathbf{1 0}$ driving the reaction to completion. In the absence of the bidentate nucleophile, only traces of the alkynones 11 were recovered. ${ }^{18}$

In 2005, Kiselyov reported an efficient one-pot approach for the synthesis of 2,4,6-trisubstituted and 2,4,5,6-tetrasubstituted pyrimidines 18 (Scheme 4). ${ }^{19}$ Reaction of alkyl- or benzylphosphonates 13 with aryl nitriles 12 formed unstable aza-Wittig species 14 which were converted into $\alpha, \beta$-unsaturated imines 16 by reaction with aromatic aldehydes $\mathbf{1 5}$. The latter intermediates were converted into the desired pyrimidine derivatives after nucleophilic attack by a bidentate nuclophile $\mathbf{1 7}$, usually guanidine or amidine.

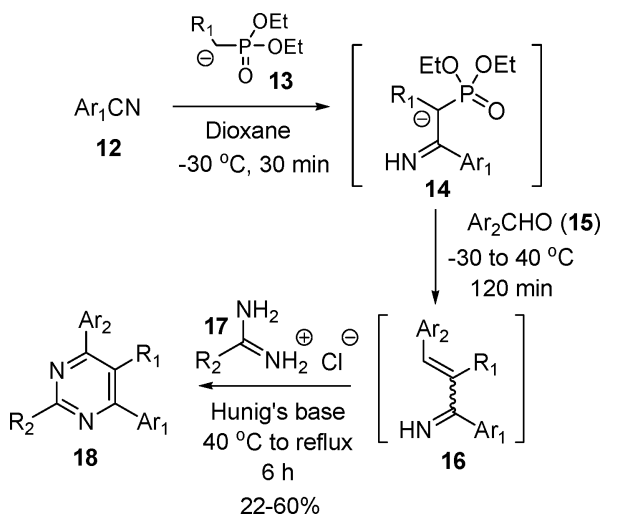

Scheme 4 Kiselyov's synthesis of 2,4,6-trisubstituted and 2,4,5,6tetrasubstituted pyrimidines.

Apart from a very old strategy reported by Eilingsfeld et al. in $1968,{ }^{20}$ the synthetic approach defined by Path B (1,2/2,3-bond forming) count for very few examples in the literature. Recently, the Palacios group reported an interesting approach for the synthesis of 4,5-dihydro-2-pyrimidinones $\mathbf{2 3}$ in which the key step was represented by the aza-Michael addition of substituted amines to 1-azadienes (Scheme 5). ${ }^{21}$ Starting from the $\alpha$-ketophosphonate 18, enamines 22 were obtained in a multicomponent reaction: addition of the phosphazene $\mathbf{2 0}$ (generated in situ) to a solution of 18 afforded the $\beta, \gamma$-unsaturated iminophosphonate intermediate 21 which, by addition of substituted amines, gave the enamines 22 . The latter compounds were then cyclized by reaction with triphosgene in the presence of triethylamine to give the phosphonylated pyrimidinones 23.

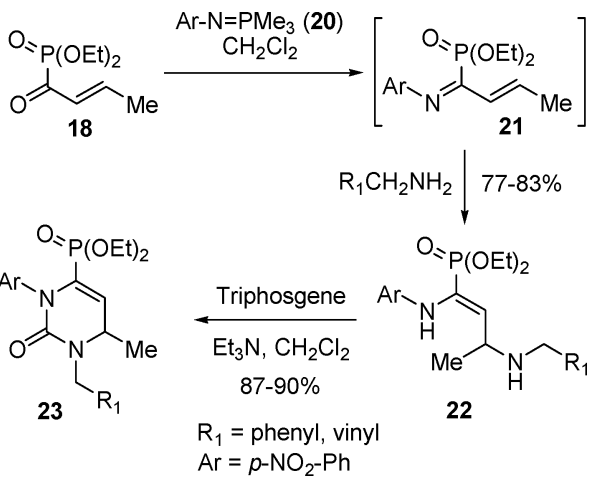

Scheme 5 Palacios's synthesis of 1,3,4,6-tetrasubstituted pyrimidinones.

A versatile synthetic approach following Path C $(1,2 /$ 3,4-bond forming) has been reported by the Deniaud group: the $S$-methyl diazadienium iodide $\mathbf{2 4}$ was cyclized by reaction with isocyanates or isothiocyanates in basic medium to give the corresponding N1-substituted derivatives 25 (Scheme 6). ${ }^{22}$ This approach worked well for aromatic isocyanates/isothiocyanates and sugar-isothiocyanates while, in the case of alkyl isocyanates, a two step protocol was necessary in order to cyclize the linear intermediate by addition of a strong base $(\mathrm{NaH})$. A wide range of pyrimidine derivatives and corresponding nucleosides were also obtained by further elaboration of the heterocyclic ring.

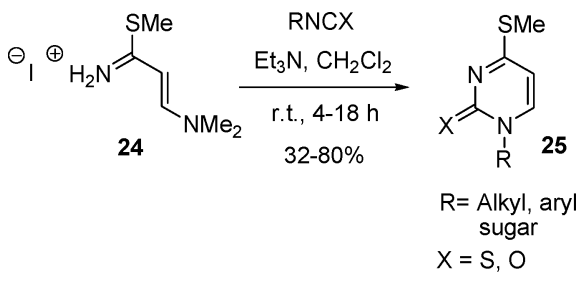

Scheme 6 Deniaud's synthesis of 1,4-disubstituted pyrimidines.

A nice approach for the synthesis of trisubstituted or tetrasubstituted pyrimidines following Path D (3,4/4,5-bond forming) has been recently reported by Sakai et al. which generated the pyrimidine scaffold by condensation of an acetal with vinyl amidines 30 (Scheme 7). ${ }^{23}$ The latter compound was obtained in a one-pot procedure reacting functionalized silane $\mathbf{2 6}$ with benzonitrile 27 in the presence of butyllithium to obtain the

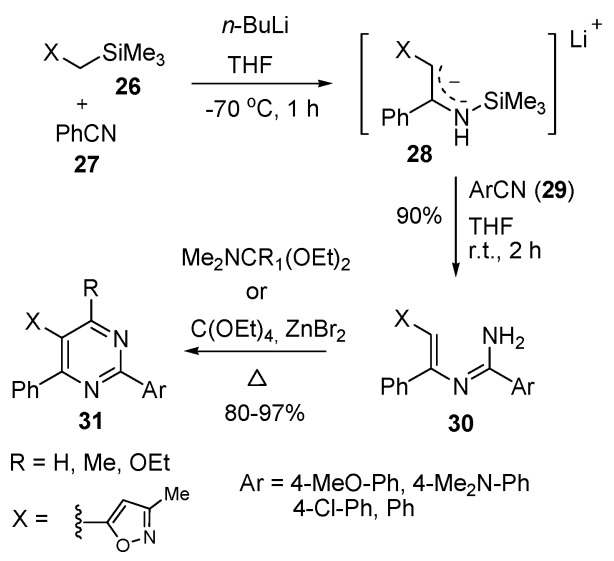

Scheme 7 Sakai's synthesis of 2,5,6-trisubstituted pyrimidines and 2,4,5,6-tetrasubstituted pyrimidines. 
1-azaallyl anion intermediates $\mathbf{2 8}$ that were converted in the desired amidines $\mathbf{3 0}$ by reaction with aromatic nitriles $\mathbf{2 9}$. In the final step, the substituted amidines were cyclized by heating with different $\mathrm{N}, \mathrm{O}$-acetals, with or without the presence of additives depending on the acetal employed, to give highly functionalized pyrimidine derivatives $\mathbf{3 1}$.

Among the synthetic approaches following Path E (3,4/ 5,6-bond forming) a few interesting procedures can be mentioned. The protocol developed by the Muchowski group is based on the thermal $[4 \pi+2 \pi]$ cycloaddition reaction of 1,3-diazadienes with electron deficient acetylenes (Scheme 8) ${ }^{24}$ Both 1-substituted (34, 36) and 1-unsubstituted (32) 1,3-diaza-1,3-butadienes containing a leaving group at position 4 have been prepared as stable species and used in the heterocyclization step. The thermally sensitive $N 1$-Boc protected 1,3-diazadienes 32 were converted into the 2,5-disubstituted or 2,4,5-trisubstituted pyrimidines 33 by heating with ethyl propiolate $\left(\mathrm{R}_{2}=\mathrm{H}\right)$ or dimethyl acetylenedicarboxylate (DMAD) $\left(\mathrm{R}_{2}=\mathrm{COOEt}\right)$ respectively. Alternatively, the stable N1-unprotected 1,3-diazadienes $\mathbf{3 4}$ and $\mathbf{3 6}$ can be reacted with ethyl propiolate or DMAD to give the corresponding 2,5,6trisubstituted or 2,4,5,6-tetrasubstituted pyrimidines $\mathbf{3 5}$ and 37, respectively. ${ }^{25}$

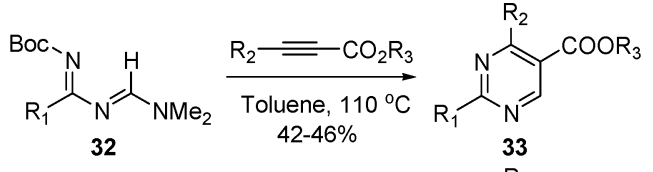

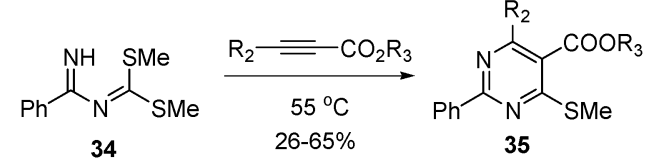

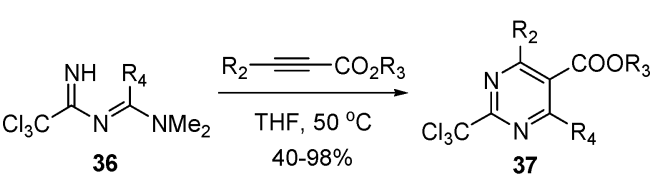

$$
\begin{aligned}
& \mathrm{R}_{1}=\mathrm{MeS}, \mathrm{Ph}, \mathrm{EtO}_{2} \mathrm{C},(\mathrm{EtO})_{2} \mathrm{CH} \quad \mathrm{R}_{3}=\mathrm{Me}, \mathrm{Et} \\
& \mathrm{R}_{2}=\mathrm{H}, \mathrm{COOMe} \quad \mathrm{R}_{4}=\mathrm{H}, \mathrm{Me}, \mathrm{Ph}
\end{aligned}
$$

Scheme 8 Muchowski's synthesis of 2,5-disubstituted-; 2,5,6-trisubstituted and 2,4,5,6-tetrasubstituted pyrimidines.

A second synthetic procedure following Path $\mathbf{E}$ was reported by Martinez et al. ${ }^{26}$ This method requires the activation of the carbonyl moiety of esters or ketones $\mathbf{3 8}$ with trifluoromethanesulfonic anhydride $\left(\mathrm{Tf}_{2} \mathrm{O}\right)$ followed by nucleophilic addition of two equivalents of nitriles $\mathbf{3 9}$ ( $\mathrm{Scheme}$ 9). Treatment of $\mathbf{3 8}$ with $\mathrm{Tf}_{2} \mathrm{O}$ is believed to give an alkoxy(trifloxy)carbenium ion which is trapped by the first equivalent of nitrile affording the nitrilium intermediate 40 which then reacts with a second molecule of nitrile to give the pyrimidines 42. This simple one-step procedure facilitated the preparation of 2,4,6-trisubstituted or 2,4,5,6-tetrasubstituted pyrimidines.

An interesting approach for the synthesis of pyrimidine-5carbonitriles 46,48 and pyrimidine-5-carboxylates 47 was reported by Krechl et al. ${ }^{27}$ Reacting the imidates $\mathbf{4 3}$ and the isocyanates $\mathbf{4 4}$ for 24 hours at room temperature or $50{ }^{\circ} \mathrm{C}$ (depending on the nature of $\mathrm{R}_{1}$ and $\mathrm{R}_{2}$ ), the $N$-substituted aminocarbonylimidates 45 were obtained after recrystallization. Treatment of the latter

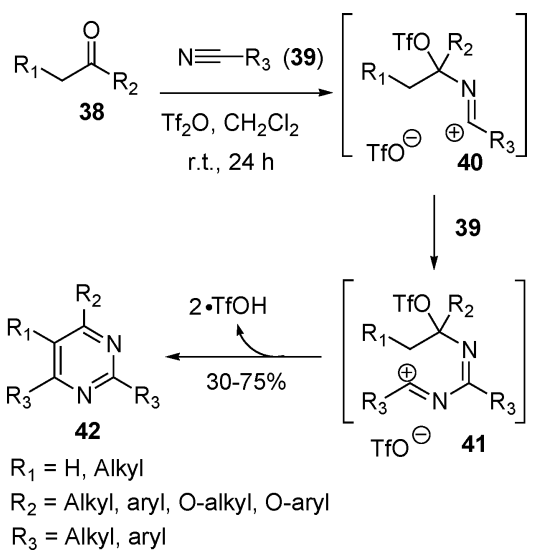

Scheme 9 Martinez's synthesis of 2,4,6-trisubstituted and 2,4,5,6-tetrasubstituted pyrimidines.

intermediate respectively with malonitrile, methyl cyanoacetate and diethyl malonate in the presence of a base, afforded the highly functionalized pyrimidine derivatives $\mathbf{4 6 - 4 8}$ (Scheme 10).

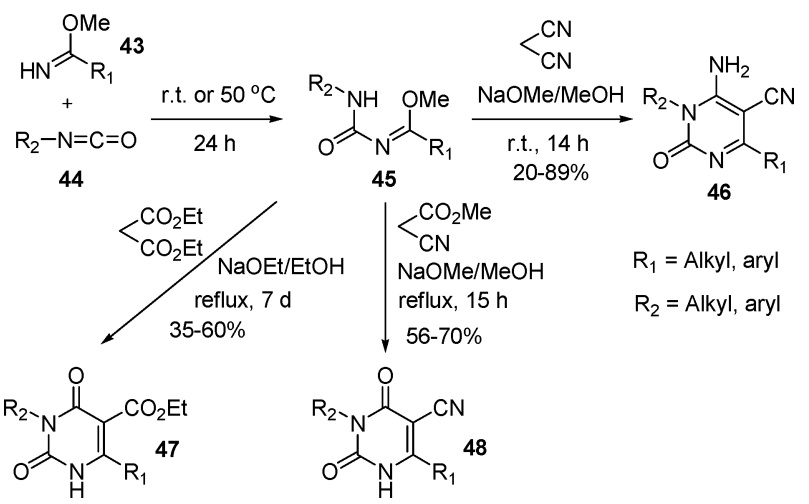

Scheme 10 Krechl's synthesis of 3,5,6-trisubstituted pyrimidines.

Among the synthetic approaches following Path $\mathbf{F}(1,2 /$ 5,6-bond forming), Ghosez et al. published a practical threecomponent synthesis of substituted pyrimidinones based on a hetero Diels-Alder reaction between 2-azadienes $\mathbf{5 1}$ and activated nitriles 52 (Scheme 11). ${ }^{28}$ In an optimized protocol, the iminoethers $\mathbf{4 9}$ and the acid chlorides $\mathbf{5 0}$ were reacted in the presence of triethylamine to give substituted 2-azadiene intermediates $\mathbf{5 1}$

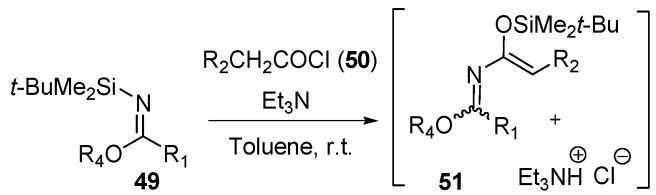

$$
\begin{aligned}
& \mathrm{R}_{1}=\mathrm{H} \text {, Me } \\
& \mathrm{R}_{2}=\mathrm{H} \text {, alkyl, halogen } \\
& \mathrm{R}_{3}=p \text {-Tos, } \mathrm{CCl}_{3}, \mathrm{CO}_{2} \mathrm{Et} \\
& \mathrm{R}_{4}=i \text { - } \mathrm{Pr} \text {, Et }
\end{aligned}
$$

Scheme 11 Ghosez's synthesis of 2,6- and 5,6-disubstituted pyrimidines. 
which were converted into the desired pyrimidines 54 by heating in the presence of the appropriate nitriles $\mathbf{5 2}$. This one-pot procedure requires the removal of the triethylamine hydrochloride and excess triethylamine before the addition of the dienophile in order to minimize the formation of decomposition products.

A mild single-step pyrimidine synthesis following Path $\mathbf{F}$ has been developed by Movassaghi et al. and is based on the trapping of highly activated amide derivatives $\mathbf{5 7}$ with weakly nucleophilic nitriles 58 to give 2,5,6-trisubstituted and 2,4,5,6-tetrasubstituted pyrimidine derivatives $\mathbf{6 0}$ (Scheme 12) ${ }^{29}$ Activation of the amides 55 with triflic anhydride and addition of 2-chloropyridine to the resulting imidoyl triflates $\mathbf{5 6}$ was envisioned to give the highly electrophilic 2-chloropyridinium adducts 57. Addition of the nitriles $\mathbf{5 8}$ to the latter intermediate and loss of 2-ClPyr-TfOH affords nitrilium triflate salts $\mathbf{5 9}$, which undergo annulation to give the desired pyrimidine derivatives $\mathbf{6 0}$. A wide range of nitriles and amides were shown to be compatible with this chemistry giving access to highly functionalized and also enantiopure products.
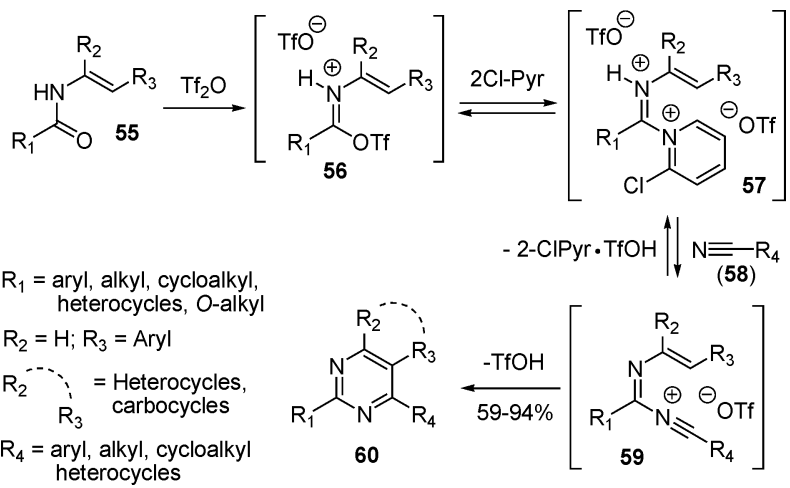

Scheme 12 Movassaghi's synthesis of 2,5,6-trisubstituted and 2,4,5,6tetrasubstituted pyrimidines.

A series of convergent approaches that do not fit in the classification reported at the beginning of this chapter can be mentioned as alternative procedures for the synthesis of substituted pyrimidines.

The Ley group reported a simple and scaleable route for the preparation of 2,5,6-trisubstituted-4-aminopyrimidines: treatment of a neat sample of aliphatic or aromatic nitriles $\mathbf{6 1}$ with a catalytic amount $(5 \mathrm{~mol} \%)$ of potassium tert-butoxide at $165^{\circ} \mathrm{C}$ via microwave irradiation (three cycles of $15 \mathrm{~min}$ each) gave the 4-aminopyrimidines $\mathbf{6 2}$ after a simple filtration from the reaction mixture (Scheme 13). ${ }^{30}$

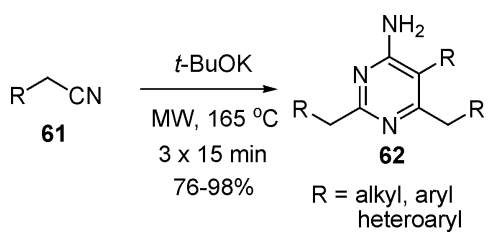

Scheme 13 Ley's synthesis of 2,5,6-trisubstituted pyrimidines.

Kakiya et al. reported an efficient approach to the synthesis of 2,4,6-trisubstituted pyrimidines $\mathbf{6 9}$, the reaction of $\alpha, \alpha$-dibromo oxime ethers 63 with a variety of Grignard reagents (Scheme 14). ${ }^{31}$ Using 2.2 equivalents of the Grignard reagents at $-42{ }^{\circ} \mathrm{C}$ and warming up the reaction mixture to room temperature, the pyrimidines 69 were obtained in moderate to good yields.

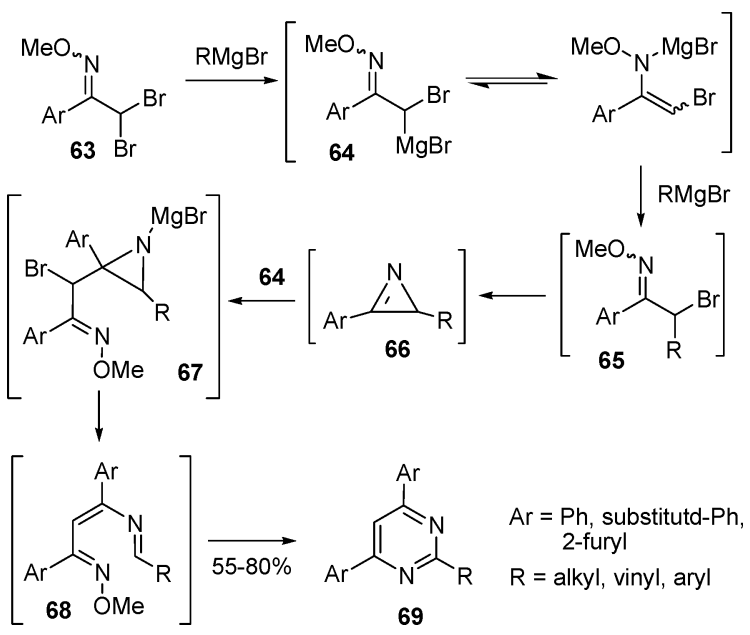

Scheme 14 Kakiya's synthesis of 2,4,6-trisubstituted pyrimidines.

Mechanistically, after an initial $\mathrm{Br}-\mathrm{Mg}$ exchange, alkylation at the $\alpha$-position of the carbenoid gave the intermediate $\mathbf{6 5}$ which cyclized and then reacted with $\mathbf{6 4}$ to give the intermediate $\mathbf{6 8}$. Ring opening, and final $6 \pi$-pericyclic ring closure with elimination of methanol, gave the desired pyrimidines $\mathbf{6 9}$.

Recently, Blangetti et al. exploited the reactivity of $\alpha, \beta$ unsaturated acetals for a one-pot three component synthesis of pyrimidines (Scheme 15). ${ }^{32}$ Reacting crotonaldehyde acetal 70 with 2 equivalents of nitriles $\mathbf{7 1}$ in the presence of the Schlosser's superbase (LIC-KOR) afforded the desired 2,4,5,6tetrasubstituted pyrimidines $\mathbf{7 5}$. Initial metalation and addition of the first molecule of nitrile gave the $N$-metalketimine $\mathbf{7 2}$ which, upon addition of a second molecule of nitrile, cyclization and spontaneous oxidation, gave the pyrimidines $\mathbf{7 5}$.

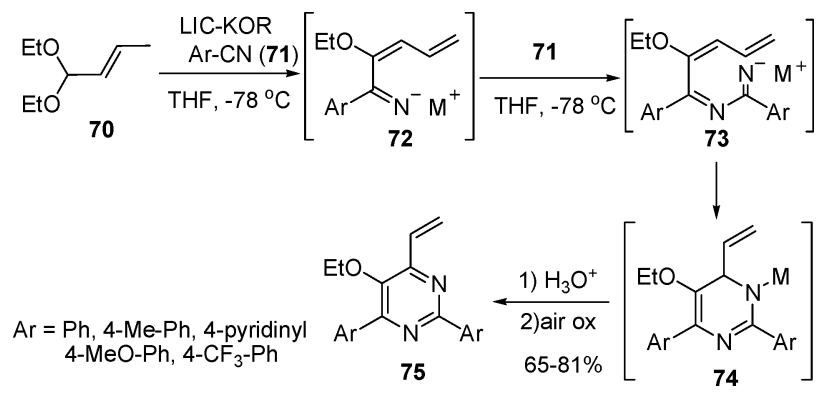

Scheme 15 Blangetti's synthesis of 2,4,5,6-tetrasubstituted pyrimidines.

Another synthetic strategy formally belonging to path A but not employing a bidentate nucleophile (characteristic of the Pinner-like approaches) has been recently developed by Rossi et al. (Scheme 16). ${ }^{33}$ Aza-Wittig condensation of the $N$-triphenylphosphoraniliden-benzamidine $\mathbf{7 6}$ with $\alpha, \beta$-unsaturated aldehydes $\mathbf{7 7}$ gave the azatriene intermediates $\mathbf{7 8}$ which, after electrocyclic ring closure and oxidation, afforded the 2,5-disubstituted or 2,4,5trisubstituted pyrimidines $\mathbf{7 9}$.

\section{Pyrimidine functionalization}

Complementary approaches for the synthesis of substituted pyrimidines involve the use of recent advances in cross-coupling chemistry or direct functionalization of a preformed pyrimidine 


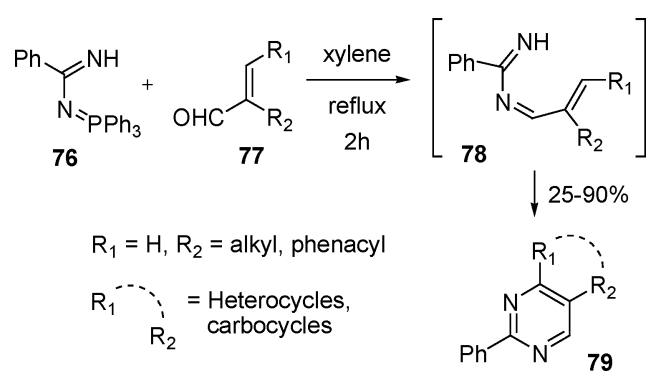

Scheme 16 Rossi's synthesis of 2,5-disubstituted and 2,4,5-trisubstituted pyrimidines.

scaffold in order to access those derivatives otherwise difficult to obtain using the convergent approaches described in the previous section.

The Knochel group has recently reported an efficient procedure allowing the direct functionalization of all positions of the pyrimidine ring via successive regio- and chemoselective magnesiation followed by trapping with specific electrophiles (Scheme 17). ${ }^{34}$

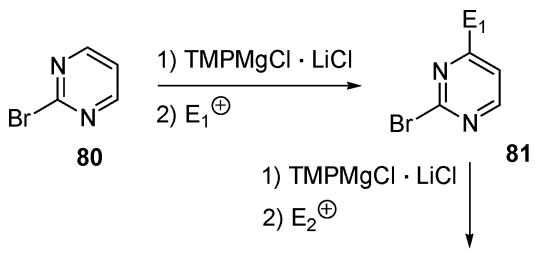

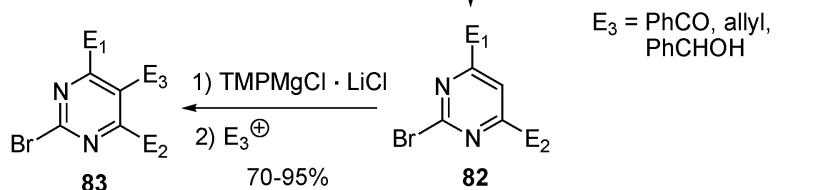

Scheme 17 Multiple functionalization of pyrimidines via subsequent magnesiation and trapping with electrophiles.

Starting from the simple 2-bromopyrimidine 80, reaction with 1.1 equivalents of TMPMgCl$\cdot \mathrm{LiCl}$ led to the 4-magnesiated species which was then trapped with various electrophiles $\left(E_{1}\right)$ to give the 4-substituted compound 81. A second magnesiation/trapping sequence occurred selectively at the C6 position allowing the generation of different 4,6-disubstituted derivatives 82. The last available position (C5) can be functionalized with the electrophiles $\mathrm{E}_{3}$ following the same magnesiation/trapping protocol to give 4,5,6-trisubstituted compounds 83. Finally, the bromine at position 2 can be submitted to a Negishi or a Sonogashira reaction to give 2,4,5,6-tetrasubstituted pyrimidines.

With the aim of generating a diversity-oriented library of pyrimidine derivatives for pharmaceutical purposes, our research group has been long working on the functionalization of easily accessible pyrimidinones. Functionalization of the $\mathrm{C} 5$ position was obtained via a direct microwave assisted iodination: irradiation of a series of pyrimidinones and pyrimidine nucleosides 84 with $N$-iodosuccinimide at $200 \mathrm{~W}$ gave the desired 5-iodo derivatives 85 after only 3 minutes (Scheme 18). ${ }^{35}$ The latter intermediates were then converted into the corresponding 5-substituted or 4,5-disubstituted derivatives applying a microwave-enhanced Sonogashira protocol. ${ }^{36}$ Irradiation of the 5-iodo derivatives $\mathbf{8 5}$ with the appropriate alkyne in the presence of $\mathrm{Et}_{3} \mathrm{~N}, \mathrm{PdCl}_{2}\left(\mathrm{PPh}_{3}\right)_{2}$ and $\mathrm{CuI}$ for 5 minutes at $40{ }^{\circ} \mathrm{C}$ gave respectively the bicyclic

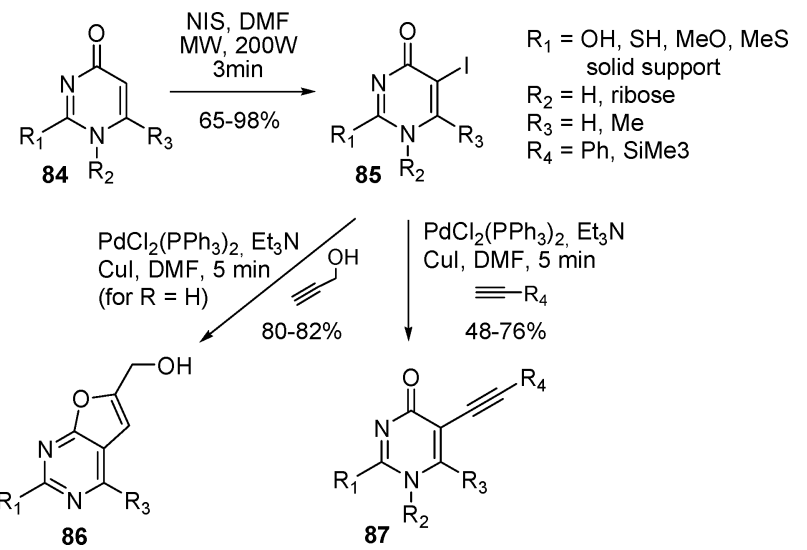

Scheme 18 Pyrimidinone functionalization via microwave-assisted iodination and Sonogashira coupling.

derivatives $\mathbf{8 6}$ (using propargyl alcohol) or the 5-alkynyl derivatives 87 (using trimethylsilyl acetylene or 2-propynylbenzene).

Another example of the versatility of simple pyrimidinones in the diversity-oriented synthesis of anti-HIV drugs is reported in Scheme 19. Starting from the readily available compound $\mathbf{8 8}$, selective tosylation in $\mathrm{C} 4$ afforded the key intermediate $\mathbf{8 9}$ which was used as starting material of a combinatorial protocol: nucleophilic substitution at $\mathrm{C} 4$ with different amines, dehydration at C6 with sodium hydride and finally sulfur-oxidation with Oxone afforded a small library of 2,4,6-trisubstituted pyrimidines $91 .{ }^{37}$ Biological evaluation of this library led to the identification of a promising anti-HIV inhibitor endowed with an unprecedented mechanism of action. ${ }^{38}$ Further functionalization at the $\mathrm{C} 2$ and C6 positions was also accessible: oxidation of $\mathbf{9 0}$ with Oxone and subsequent nucleophilic displacement with sodium hydrosulfide afforded the 2-thiol intermediate which was converted into<smiles>CSc1nc(C(C)(C)O)cc(=O)[nH]1</smiles>

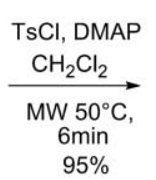

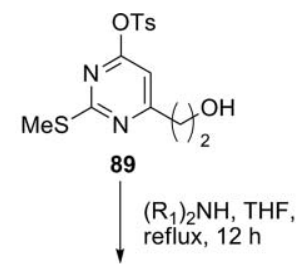<smiles>[R7]N([R7])c1cc(C=C)nc(S(C)(=O)=O)n1</smiles>

1) $\mathrm{NaH}$, dioxane $\mathrm{NaH}$, dioxan, $3 \mathrm{~h}$
reflux, 2) Oxone<smiles>[R][R](N([R])[R])N([R])CCc1cc(N([R])[R])nc(N([R])[R])n1</smiles>

$\mathrm{MeOH} / \mathrm{H}_{2} \mathrm{O}$ $80-95 \%$<smiles>[R]N([R])c1cc(C(C)O)nc(S(C)(=O)=O)n1</smiles>
1) Oxone $\mathrm{MeOH} / \mathrm{H}_{2} \mathrm{O}$ 3) Benzyl bromides r.t., $3 \mathrm{~h}, 54 \% \quad \mathrm{~K}_{2} \mathrm{CO}_{3}$ DMF, MW 2) $\mathrm{NaS}, \mathrm{H}_{2} \mathrm{O}$ reflux, $2 \mathrm{~h}, 64 \%$, $130{ }^{\circ} \mathrm{C}, 5 \mathrm{~min}$.<smiles>[R9]c1cccc(CSc2nc(C([Y4])O)cc(N([R])[R])n2)c1</smiles>

$\mathrm{R}_{1}=$ alkyl, allyl, benzyl

$\mathrm{R}_{2}=$ alkyl

$\mathrm{R}_{3}=4-\mathrm{MeO}, 4-\mathrm{NO}_{2}$

Scheme 19 Combinatorial functionalization of simple pyrimidinones. 
2-benzylthio derivatives 92 via microwave assisted alkylation. ${ }^{39}$ In addition, by heating the sulfone $\mathbf{9 2}$ with an excess of amine, it was possible to obtain compound $\mathbf{9 3}$ after a preliminary Michael addition on the vinyl group followed by nucleophilic displacement in $\mathrm{C} 2$.

\section{Conclusions}

This perspective article has attempted to highlight the recent development in the synthesis of highly functionalized pyrimidines which represent a privileged scaffold for the identification of pharmacologically active compounds. The complementarity of convergent approaches and direct functionalization of the pyrimidine scaffold facilitates the generation of a wide range of functionalized pyrimidine derivatives.

\section{Acknowledgements}

The authors wish to thank the Italian Ministero dell'Istruzione, dell'Università e della Ricerca (PRIN 2007N7KYCY) and the FLUINHIBIT FP7 project (HEALTH-F3-2008-201634) for financial support.

\section{Notes and references}

1 (a) R. Gmelin and Z. Hoppe-Seyler's, Physiol. Chem., 1959, 316, 164; (b) E. A. Bell and R. G. Foster, Nature, 1962, 194, 91.

2 B. C. P. Jansen and W. F. Donath, Chem. Weekblad., 1926, 23, 201.

3 F. Tanaka, S. Takeuchi, N. Tanaka, H. Yonehara, H. Umezawa and Y. J. Sumiki, Antibiot. A, 1961, 14, 161.

4 (a) Y.-L. Lin, R.-L. Huang, C.-M. Chang and Y.-H. Kuo, J. Nat. Prod., 1997, 60, 982; (b) R. G. S. Gerlinck, J. C. Braekman, D. Daloze, I. Bruno, R. Riccio, D. Rogeau and P. Amade, J. Nat. Prod., 1992, 55, 528.

5 (a) I. Ohtani, R. E. Moore and M. T. C. Runnegar, J. Am. Chem. Soc., 1992, 114, 7941; (b) R. Banker, B. Teltsch, A. Sukenik and S. Carmeli, J. Nat. Prod., 2000, 63, 387.

6 (a) G. Brugnatelli, Giornale di fisica chimica, et storia Naturale (Pavia) decada seconda, 1818, 1, 117; (b) G. Brugnatelli, Ann. Chim. Phys., $1818,8,201$.

7 E. Frankland and H. Kolbe, Justus Liebigs Ann. Chem., 1848, 65, 269. 8 M. Radi, G. Maga, M. Alongi, L. Angeli, A. Samuele, S. Zanoli, L. Bellucci, A. Tafi, G. Casaluce, G. Giorgi, M. Armand-Ugon, E. González-Ortega, J. A. Esté, M. Baltzinger, G. Bec, P. Dumas, E. Ennifar and M. Botta, J. Med. Chem., 2009, 52, 840.

9 U. Koch, B. Attenni, S. Malancona, S. Colarusso, I. Conte, M. Di Filippo, S. Harper, B. Pacini, C. Giomini, S. Thomas, I. Incitti, L. Tomei, R. De Francesco, S. Altamura, V. G. Matassa and F. Narjes, J. Med. Chem., 2006, 49, 1693.

10 X.-J. Chu, W. DePinto, D. Bartkovitz, S.-S. So, B. T. Vu, K. Packman, C. Lukacs, Q. Ding, N. Jiang, K. Wang, P. Goelzer, X. Yin, M. A. Smith, B. X. Higgins, Y. Chen, Q. Xiang, J. Moliterni, G. Kaplan, B. Graves, A. Lovey and N. Fotouhi, J. Med. Chem., 2006, 49, 6549.

11 G. M. P. Giblin, C. T. O’Shaughnessy, A. Naylor, W. L. Mitchell, A. J. Eatherton, B. P. Slingsby, D. A. Rawlings, P. Goldsmith, A. J. Brown, C. P. Haslam, N. M. Clayton, A. W. Wilson, I. P. Chessell, A. R. Wittington and R. Green, J. Med. Chem., 2007, 50, 2597.
12 P. A. Harris, A. Boloor, M. Cheung, R. Kumar, R. M. Crosby, R. G. Davis-Ward, A. H. Epperly, K. W. Hinkle, R. N. Hunter, J. H. Johnson, V. B. Knick, C. P. Laudeman, D. K. Luttrell, R. A. Mook, R. T. Nolte, S. K. Rudolph, J. R. Szewczyk, A. T. Truesdale, J. M. Veal, L. Wang and J. A. Stafford, J. Med. Chem., 2008, 51, 4632.

13 (a) L. C. W. Chang, R. F. Spanjersberg, J. K. von Frijtag Drabbe, T. Künzel, Mulder-Krieger, G. van den Hout, M. W. Beukers, J. Brussee and A. P. Ijzerman, J. Med. Chem., 2004, 47, 6529; (b) M. C. Lanier, M. Moorjani, Z. Luo, Y. Chen, E. Lin, J. E. Tellew, X. Zhang, J. P. Williams, R. S. Gross, S. M. Lechner, S. Markison, T. Joswig, W. Kargo, J. Piercey, M. Santos, S. Malany, M. Zhao, R. Petroski, M. I. Crespo, J.-L. Diaz, J. Saunders, J. Wen, Z. O'Brien, K. Jalali, A. Madan and D. H. Slee, J. Med. Chem., 2009, 52, 709; (c) B. Cosimelli, G. Greco, M. Ehlardo, E. Novellino, F. Da Settimo, S. Taliani, C. La Motta, M. Bellandi, T. Tuccinardi, A. Martinelli, O. Ciampi, M. L. Trincavelli and C. Martini, J. Med. Chem., 2009, 51, 1764.

14 A. S. Karpov and T. J. J. Müller, Synthesis, 2003, 18, 2815.

15 A. S. Karpov and T. J. J. Müller, Org. Lett., 2003, 5, 3451.

16 M. C. Bagley, C. Brace, J. W. Dale, M. Ohnesorge, N. G. Phillips, X. Xiong and J. Bower, J. Chem. Soc. Perkin Trans. 1, 2002, 2, 1663.

17 M. C. Bagley, D. D. Hughes and P. H. Taylor, Synlett, 2003, 2, 259.

18 M. C. Bagley, D. D. Hughes, H. M. Sabo, P. H. Taylor and X. Xiong, Synlett, 2003, 10, 1443.

19 A. S. Kiselyov, Tetrahedron Lett., 2005, 46, 1663.

20 H. Eilingsfeld, M. Patsch and H. Scheuermann, Chem. Ber., 1968, 101, 2426.

21 J. Vicario, D. Aparicio and F. Palacios, J. Org. Chem., 2009, 74, 452.

22 A. Robin, K. Julienne, J.-C. Meslin and D. Deniaud, Eur. J. Org. Chem., 2006, 3, 634 .

23 N. Sakai, Y. Aoki, T. Sasada and T. Konakahara, Org. Lett., 2005, 7, 4705.

24 A. Guzmán, M. Romero and F. X. Talamás, J. Org. Chem., 1996, 61, 2470.

25 A. Guzman, M. Romero and F. X. Talamas, Tetrahedron Lett., 1992, 33, 3449

26 A. G. Martinez, A. H. Fernández, R. M. Alvarez, M. D. M. Vilchez, M. L. L. Gutierrez and L. R. Subramanian, Tetrahedron, 1999, 55, 4825.

27 J. Krechl, M. A. Perez, F. J. Cuadrado and J. L. Soto, Synthesis, 1988, 122.

28 L. Ghosez, E. Jnoff, P. Bayard, F. Sainte and R. Beaudegnies, Tetrahedron, 1999, 55, 3387.

29 M. Movassaghi and M. D. Hill, J. Am. Chem. Soc., 2006, 128, 14254.

30 I. R. Baxendale and S. V. Ley, J. Comb. Chem., 2005, 7, 483.

31 H. Kakiya, K. Yagi, H. Shinokubo and K. Oshima, J. Am. Chem. Soc., $2002,124,9032$

32 M. Blangetti, A. Deagostino, C. Prandi, C. Zavattaro and P. Venturello, Chem. Commun., 2008, 14, 1689.

33 E. Rossi, G. Abbiati and E. Pini, Synlett, 1999, 8, 1265

34 (a) M. Mosrin and P. Knochel, Org. Lett., 2008, 10, 2497; (b) M. Mosrin and P. Knochel, Chem. Eur. J., 2009, 15, 1468; (c) N. Boudet and P. Knochel, Org. Lett., 2006, 8, 3737.

35 L. Paolini, E. Petricci, F. Corelli and M. Botta, Synthesis, 2003, 7, 1039.

36 E. Petricci, M. Radi, F. Corelli and M. Botta, Tetrahedron Lett., 2003 , 44, 9181 .

37 M. Radi, E. Petricci, G. Maga, F. Corelli and M. Botta, J. Comb. Chem., $2005,7,117$.

38 G. Maga, M. Radi, S. Zanoli, F. Manetti, R. Cancio, U. Hübscher, S. Spadari, C. Falciani, M. Terrazas, J. Vilarrasa and M. Botta, Angew. Chem. Int. Ed., 2007, 46, 1810.

39 M. Radi, C. Falciani, L. Contemori, E. Petricci, G. Maga, A. Samuele, S. Zanoli, M. Terrazas, M. Castria, A. Togninelli, J. A. Esté, I. ClotetCodina, M. Armand-Ugón and M. Botta, ChemMedChem, 2008, 3, 573. 